\title{
Metodologías activas y multiliteraturas en los procesos de formación inicial del profesorado
}

\author{
Ricardo Jorge de Sousa Cavalcanti(*) \\ ricardo.cavalcanti@ifal.edu.br \\ https://orcid.org/0000-0001-6990-6669 \\ Rossana Viana Gaia ${ }^{(*)}$ \\ rossana.gaia@ifal.edu.br \\ https://orcid.org/0000-0001-7592-1881 \\ Paulo Diego Cassiano Neves ${ }^{(*)}$ \\ pdcn1@aluno.ifal.edu.br \\ https://orcid.org/0000-0001-8652-1779 \\ Susan Maria Silva Valença(*) \\ smsv1@aluno.ifal.edu.br \\ https://orcid.org/0000-0003-4970-8256 \\ ${ }^{(*)}$ Instituto Federal de Educação, Ciência e Tecnologia de Alagoas - Ifal, Campus Maceió/AL \\ Brasil
}

Recebido: 30/03/2021 Aceito: 30/09/2021

\section{Resumen}

Hay un paradigma diferenciado para el campo de la educación global, a partir de la pandemia por Covid-19. El uso de tecnologías con finalidades educativas puede ser identificado en estudios diversificados como práctica efectiva, aunque en distintas realidades. De esta manera, el presente estudio analiza necesidades emergentes de los profesores en formación, con base en datos observados en la oferta de un curso breve en línea sobre multiliteraturas, Base Nacional Común Curricular (en adelante BNCC) y metodologías activas. Los datos analizados integran resultados parciales de la investigación "El uso de metodologías activas en procesos de formación inicial docente en el curso de Letras: El producto educacional curso breve on-line". La propuesta integra el pliego del Programa Institucional de Becas de Iniciación en Desarrollo Tecnológico e Innovación - PIBITI, con el uso de la metodología de la investigación-acción e investigación bibliográfica sobre multiliteraturas, metodologías activas y enseñanza híbrida. El objetivo de la propuesta de este curso breve modular fue posibilitar reflexiones de perspectiva netnográfica en la enseñanza a los alumnos matriculados de los períodos iniciales, del curso licenciatura en Letras del Instituto Federal de Alagoas - Ifal, en el período de noviembre de 2020. El foco de este análisis está centrado en procesos comunicativos a partir de las interacciones de los alumnos-alumnos entre sí y entre los alumnos-profesores. El estudio es cualitativo e incluye análisis del trabajo de conclusión de los alumnos, en formato artículos de opinión. Los resultados demuestran la importancia de los temas abordados para la formación docente.

Palabras-clave: Metodologías activas, cursos múltiples, educación híbrida, educación remota de emergencia. 


\title{
METODOLOGIAS ATIVAS E MULTILETRAMENTOS EM PROCESSOS DE FORMAÇÃO INICIAL DOCENTE
}

\begin{abstract}
Resumo
Há um paradigma diferenciado para o campo da educação global, a partir da pandemia por Covid-19. O uso de tecnologias com finalidades educativas pode ser identificado em estudos diversificados como prática efetiva, ainda que em distintas realidades. O presente estudo analisa necessidades emergentes dos professores em formação, com base em dados observados na oferta de minicurso on-line sobre multiletramentos, Base Nacional Comum Curricular (doravante BNCC) e metodologias ativas. Os dados analisados integram resultados parciais da pesquisa "O uso de metodologias ativas em processos de formação inicial docente no curso de Letras: O produto educacional minicurso on-line". A proposta integra o edital do Programa Institucional de Bolsas de Iniciação em Desenvolvimento Tecnológico e Inovação - PIBITI, com uso da metodologia da pesquisa-ação e investigação bibliográfica sobre multiletramentos, metodologias ativas e ensino híbrido. O objetivo da proposta de minicurso modular foi possibilitar reflexões de perspectiva netnográfica no ensino aos alunos matriculados dos períodos iniciais, do curso licenciatura em Letras do Instituto Federal de Alagoas - Ifal, no período de novembro de 2020. O foco desta análise está centrado em processos comunicativos a partir das interações dos alunos-alunos entre si e entre os alunos-professores. $\mathrm{O}$ estudo é qualitativo e inclui análise do trabalho de conclusão dos alunos, no formato artigos de opinião. Os resultados comprovam a importância dos temas abordados para a formação docente.
\end{abstract}

Palavras-chave: Metodologias ativas, multiletramentos, ensino híbrido, ensino remoto emergencial.

\section{ACTIVE AND MULTILAYERED METHODOLOGIES IN INITIAL TEACHER EDUCATION PROCESSES}

\begin{abstract}
There is a different paradigm for the global education field, starting with the Covid-19 pandemic. The use of technologies for educational purposes can be identified in diverse studies as effective practice, even in different realities. The present study analyzes the emerging needs of teachers in training, based on data observed in the offer of an online mini-course on multicourses, the National Common Curricular Base (BNCC in Brazil) and active methodologies. The analyzed data integrate partial results of the research "The use of active methodologies in initial teacher education processes in the Literature course: The educational product on-line mini course" - PIBITI, using action research methodology and bibliographic research on multicourses, active methodologies and hybrid teaching. The objective of the modular mini-course proposal was to allow reflections from a netnographic perspective in teaching students enrolled in the initial periods, in the Licenciatura em Letras course from the Federal Institute of Alagoas - Ifal, in the period of November 2020. The focus of this analysis is centered on communicative processes based on the interactions of students-students with each other and between studentteachers. The study is qualitative and includes work analysis of completion of students, in the form of opinion articles. The results prove the importance of that of the topics addressed for teacher training.
\end{abstract}

Keywords: Active methodologies, multi-courses, hybrid education, emergency remote education. 


\section{Introdução}

O uso de metodologias ativas e sua relação com ensino em formatos híbridos, conforme indicam os estudos da área (MORAN, 2018; FALCÃO, 2017), apresentam-se como possibilidade de garantir processos de ensino-aprendizagem em fases críticas, como o momento da Pandemia por Covid-19. Nesse sentido, a organização de um minicurso on-line sobre o tema e a oferta a graduandos em períodos iniciais do curso de Letras - Português, do Instituto Federal de Alagoas, inclui a ideia de pensar práticas pedagógicas inovadoras a respeito dos multiletramentos.

Segundo Rojo (2012, p. 12), o conceito de multiletramentos aborda dois tipos de diversidade: a cultural e a dos formatos existentes de textos. Após março de 2020, quando a ocorrência da pandemia obrigou escolas a paralisarem atividades, alunos inscritos em cursos presenciais precisaram rever perspectivas de aprendizagem na prática de aulas ministradas remotamente, por conta das medidas de distanciamento social necessárias para evitar a disseminação do novo Coronavírus. No entanto, parte desses alunos está inscrita nesse formato de ensino justamente por sentirem dificuldade em formatos de ensino a distância. Mesmo que Costa (2020, p.12) explique a distinção entre o Ensino Remoto Emergencial (a partir de agora, ERE) e a Educação a Distância (a partir de agora, EaD), bem como a relevância de entender que não basta aos professores elaborarem uma transposição do ensino presencial para a internet, constata-se que os alunos, por estarem em ambiente virtual, identificam semelhança com a EaD, principalmente se a instituição de ensino proceder a essa transformação do ambiente de forma abrupta restringindo a prática a transmitir as aulas ao vivo pela internet.

Atualmente, o conhecimento sobre Tecnologias Digitais de Informação e Comunicação (a partir de agora, (TDIC)), tanto para aquisição de conhecimentos quanto para produção de material didático, aula e atividades que promovam uma maior participação dos alunos, tem sido uma necessidade para professores em formação. A Base Nacional Comum Curricular (a partir de agora, BNCC), cuja estrutura está disponível na plataforma do Ministério da Educação (BRASIL, 2018) destaca que os alunos devem aprender a usar as TDIC de forma crítica. Para apoiar as escolas a alcançarem tal objetivo, o Centro de Inovação para Educação Brasileira (CIEB) criou o Currículo de Referência em Tecnologia e Computação, que prevê três eixos alinhados às competências presentes na BNCC. 
Ricardo Jorge de Sousa Cavalcanti; Rossana Viana Gaia; Paulo Diego Cassiano Neves; Susan Maria Silva Valença

Um dos objetivos deste estudo é refletir sobre o processo de apropriação e uso de conceitos relativos ao ciberespaço, pois, ainda que as pessoas usem ferramentas tecnológicas em seus cotidianos, a transposição de seu uso para as "salas de aula" não ocorre de forma simples e óbvia, o que requer adaptações para uso da tecnologia com fins educacionais. Pensar o ensino remoto remete à ideia de ubiquidade na educação, ou seja, ampliar processos de cognição humana com base em dispositivos móveis que favorecem a difusão democrática de informações e serviços, é um desafio para o setor educacional, sobretudo após a pandemia da Covid-19. Ao verificar dados históricos sobre o processo de funcionamento da sociedade global em rede, Castells (2003) destacou as relações entre mudanças sociais, tecnológicas e econômicas. Em pesquisa realizada entre 1999 e 2000, no âmbito do Instituto Federal de Alagoas, então Escola Técnica Federal de Alagoas, Gaia (2000, p. 94) já enfatizava que a presença da internet "na realidade dos estudantes no mundo inteiro não pode mais ser ignorada pela escola". A partir de março de 2020, devido à ocorrência da pandemia do Novo Coronavírus, constatou-se, principalmente nas redes públicas de ensino, a urgente necessidade de estudos práticos que contribuam para formar professores capazes de lidar com esta nova realidade, passível de muitas mudanças, sobretudo no que se refere a novas formas de comunicação e ao processo de ensinoaprendizagem.

Um aspecto necessário e que exige atenção, é que, na implementação de práticas educacionais, oriundas da cultura digital, os professores precisam se preparar para desenvolver habilidade de pesquisa, o que requer mobilização de múltiplos saberes e mudança de paradigmas. Desse modo, no ciberespaço voltado para o ensino, verifica-se a necessidade de atuação intensa do estudante, passível de ser verificada nas trilhas de participação (ou não) indicadas no AVA (Ambiente Virtual de Aprendizagem), tais como: tempo de leitura, download de textos e/ou outros materiais, participação em fóruns e encaminhamento de atividades. Esses processos não podem ser confundidos com aulas presenciais, pois, embora pareça que o estudante, ao estar em casa, teria maior disponibilidade de tempo, nem sempre isso é realidade. A partir de 2020 e enquanto perdurar a pandemia por Covid-19, o trabalho em casa tende a ser constante, em parte expressiva de atividades, assim é uma realidade que requer disciplina na organização de atividades domésticas, pois podem reduzir o tempo para estudo. Convém ainda considerar aspectos relevantes sobre a temporalidade no virtual em relação a práticas e 
atividades pedagógicas, sobretudo quando o ensino está destinado a alunos de/em licenciaturas (LUCENA, 2016), foco das nossas investigações recentes.

Outro aspecto a considerar sobre a pandemia por Covid-19 foi a necessidade de as instituições de ensino proverem ferramentas, metodologias, técnicas e diretrizes para orientar alunos e professores durante o Ensino Remoto Emergencial. No Instituto Federal de Alagoas (a partir de agora Ifal), isso ocorreu com a Resolução No 50 / 2020 (IFAL, 2020). Nesse sentido, discussões que não são recentes, mas que foram ignoradas, precisaram ser retomadas, como o uso das TDIC, ações educomunicativas em sala de aula e Comunicação Mediada por Computador (CMC). Estudo realizado pela entidade Deloitte (2019) destaca que 81\% dos entrevistados utilizam o aplicativo de mensagem Whatsapp diariamente. Estudo desenvolvido por Linhares, Chagas e Silva (2017) já indicava que, nos dados da pesquisa Tic Domicílio de 2015, 90\% dos entrevistados indicaram o uso do celular com acesso à internet como potencial para aprendizagem móvel (m-learning), dos quais 49,5\% confirmaram uso para estudos ou pesquisas acadêmicas.

Silva, Rangel e Souza (2020) relatam dificuldades encontradas na instituição de ensino onde atuam, demonstrando a necessidade de adaptar as tecnologias existentes, como um portal de ensino sem interatividade. Percebe-se como as mudanças foram forçadas por conta da pandemia, quando metodologias e tecnologias ainda inconclusas para o mundo conectado foram transpostas às pressas, corrigidas e readaptadas durante a prática. No decorrer dos relatos, é possível notar que os professores desenvolveram investigações próprias e aprenderam a utilizar as ferramentas de forma autodidata e intuitiva. Mesmo demonstrando bons resultados, se houvesse uma orientação sobre como proceder às transposições, o resultado final poderia ser menos impactante e problemático para os estudantes.

Com base nessas questões, a equipe desta pesquisa decidiu desenvolver estudos e organizar etapas para oferta de um minicurso que visa a contribuir na formação de graduandos do curso de Letras-Português no início da formação acadêmica, para que possam desenvolver e ampliar a compreensão acerca das metodologias ativas com vistas à BNCC, a partir do formato híbrido e do conhecimento sobre os multiletramentos.

Devido à proximidade dos acontecimentos, as pesquisas identificadas sobre o assunto carecem de validação pelo tempo. Contudo, houve diversas transposições de metodologias ativas que eram utilizadas no mundo off-line para permitir o uso em aulas remotas. 
Ricardo Jorge de Sousa Cavalcanti; Rossana Viana Gaia; Paulo Diego Cassiano Neves; Susan Maria Silva Valença

Destaque-se que, para desenvolver estudos sobre práticas e teorias educomunicativas com vistas à elaboração de Produto Educacional "Minicurso on-line", foram realizadas rodas de conversa virtuais e uma pesquisa bibliográfica para contribuir nos processos de sistematização de dados. O objetivo principal foi qualificar o debate e definir temáticas para formação de futuros professores da área de Letras. O propósito do minicurso foi possibilitar aos licenciandos em Letras apropriar-se de conceitos e práticas de metodologias ativas, além de refletir sobre os conceitos de hiperleitura, hiperleitor, hiperbiblioteca e hipermídia.

Por meio de pesquisa bibliográfica e aplicada, foram investigados os temas citados, elaborados os módulos do minicurso e a garantia da sua oferta aos discentes dos períodos iniciais do curso de Letras - Português (Ifal). Após a realização do módulo inicial, procedemos ao levantamento e cruzamento de dados e, por meio de uma avaliação netnográfica ${ }^{1}$, analisamos as interações dos alunos-alunos entre si e com os alunos-professores. A definição do perfil dos estudantes foi elaborada com base em questionário aplicado, no qual foram identificadas as principais dificuldades dos estudantes em relação ao formato de Ensino Remoto Emergencial.

Os resultados indicaram que, a partir da análise dos trabalhos finais entregues, e com método de abordagem qualitativa da pesquisa, o grau de aprendizagem dos cursistas sobre os temas abordados foi satisfatório e permitiu organizar ajustes para as próximas etapas do minicurso.

\section{Metodologias ativas, multiletramentos, ensino híbrido, ERE e EaD}

É possível entender que o discente aprende mais quando participa de forma ativa da aula. "Metodologias ativas são estratégias de ensino centradas na participação efetiva dos estudantes na construção do processo de aprendizagem, de forma flexível, interligada e híbrida" (MORAN, 2018. p. 41). Por meio de métodos e técnicas diversas, é possível reter mais atenção e participação dos nossos estudantes, o que se comprovou no minicurso, e isso é possível de ser realizado no ensino remoto por mediação de recursos acessíveis com TDIC.

O conhecimento sobre Metodologias Ativas permite ao docente atrair a atenção dos alunos para sua aula, aprofundar o assunto a ser abordado e provocar neles a vontade de aprender

\footnotetext{
1 - Perspectiva de estudos em que há observação quanto à recorrência de interações realizadas em AVA, por exemplo, tendo em vista aspectos ligados à acessibilidade, ao tempo de acesso e de realização de atividades, dentre outros (NOVELI, 2010).
} 
e dialogar sobre questões pertinentes ao processo de ensino-aprendizagem. Com o estudo dessas metodologias, entendemos que, nessa perspectiva metodológica, há um deslocamento do eixo tradicional que remete ao professor o centro do saber, com deslocamento para o aluno, cuja ação de pesquisa e de posicionamento se torna vital. Tais metodologias visam a substanciar o professor com técnicas que auxiliam a provocar no aluno o desejo de assumir a responsabilidade pelo seu aprendizado. Para isso, entende-se a necessidade de apresentar diversidade de materiais para realização dos estudos, com formatos como vídeos, e-books, artigos e outros formatos que contribuam para o entendimento do aluno.

Pensar a diversidade de formatos dos materiais de ensino vincula-se a multiletramentos, que apresenta duas questões essenciais: "a multiplicidade cultural das populações e a multiplicidade semiótica de constituição dos textos por meio dos quais ela se informa e se comunica" (ROJO, 2012, p.12).

No caso específico da Semiótica, constata-se essa multiplicidade no mundo off-line quando, por exemplo, temos acesso a jornais, revistas, livros, gráficos, CDs, que podem estar presentes nas mais diversas plataformas (ANECLETO; MIRANDA, 2016, p. 5). Essa quantidade de formatos exige do leitor conhecimento para interpretá-los, pois cada texto tem sua dinâmica. No mundo on-line, essa multiplicidade semiótica é ainda mais evidenciada, pois há multimídia, hiperlink, hipertexto, hipermídia em diversos formatos. O processo de aprendizagem requer de professores e estudantes a capacidade de identificar desde mapas interativos, plataformas digitais de imersão em 3D, podcasts, vídeos que podem estar gravados ou acompanhados em tempo real e outras informações possíveis de acesso no celular.

A partir dessas variáveis, entende-se a complexidade dos multiletramentos, já que as perspectivas se alteram e se mesclam, do leitor ao produtor, assim, os estudantes precisam "ler" com base em códigos diversos, o que inclui interpretar e interagir com múltiplas plataformas, além de entender como produzir nelas. Tal questão é problematizada na quinta competência da BNCC:

Compreender, utilizar e criar tecnologias digitais de informação e comunicação de forma crítica, significativa, reflexiva e ética nas diversas práticas sociais (incluindo as escolares) para se comunicar, acessar e disseminar informações, produzir conhecimentos, resolver problemas e exercer protagonismo e autoria na vida pessoal e coletiva (BRASIL, 2018, p. 9).

Os professores, a partir disso, além de lerem e produzirem, ainda precisam ensinar a produzir. É nesse ponto, em que se apresenta a necessidade de os professores ensinarem seus 
Ricardo Jorge de Sousa Cavalcanti; Rossana Viana Gaia; Paulo Diego Cassiano Neves; Susan Maria Silva Valença

alunos a produzirem conteúdo, que percebemos a importância de cursos que substanciam os docentes, ainda em período de formação, com conhecimentos e ferramentas para atuarem em um mundo conectado, pois, no âmbito do Ifal, ainda encontramos muitos estudantes sem condições tecnológicas e sociais para se apropriarem por conta própria deste mundo digital. Em nossa pesquisa, constatamos que $20 \%$ dos participantes possuíam apenas o celular como dispositivo para acesso às aulas remotas, o que limitou o uso de tecnologias interativas que pudessem ser acessadas apenas pelo computador. É importante ressaltar que o Ifal, por meio do Edital No 01/2020/DG, como forma de amenizar a situação de estudantes que têm dificuldades de acesso à internet, ofertou um auxílio conectividade para prover esse acesso a eles, disponibilizando auxílio financeiro, dispositivo para acesso à internet (tablet) ou chip $3 \mathrm{G}$ com plano de dados, conforme a necessidade atestada pelo aluno. Não adianta as intuições de ensino, públicas ou privadas, aprimorarem-se no uso da tecnologia se seus alunos não conseguirem usufruir dessa tecnologia ofertada.

As metodologias ativas, num mundo conectado e digital, expressam-se por meio de modelos de ensino híbridos, com muitas possíveis combinações. A junção de metodologias ativas com modelos flexíveis e híbridos traz contribuições importantes para o desenho de soluções atuais para os aprendizes de hoje (MORAN, 2018, p.41).

No ensino híbrido, temos diversas possibilidades de ensino, tais como: presencial, online, teórico, prático, passivo, ativo, expositiva e dialogal, cada uma tem o seu momento, e a intercalação entre as possibilidades é que torna o ensino híbrido interessante. A neurociência nos mostra que existem diversas maneiras de aprender e que cada um aprende à sua própria maneira (MORAN, 2018). Costa (2020, p. 13) apresenta um gráfico que demonstra as taxas de aprendizagem conforme o tipo de atividade. Verifica-se que, em aula expositiva, a taxa de aprendizagem é de $5 \%$ enquanto em uma leitura é de $10 \%$. O material audiovisual tem $20 \%$ de taxa de aprendizagem, uma demonstração $30 \%$ enquanto discussões em grupo atingem $50 \%$. No quesito aprender fazendo, verifica-se uma taxa de 75\%, e ensinar outra pessoa é a de maior expressividade, correspondente a $90 \%$ de taxa de aprendizagem. Note-se que, mesmo que essa gradação não corresponda a uma progressão obrigatória, não é possível aplicar apenas as formas de aprendizagem detentoras de maior taxa, como, por exemplo, não seria possível a um estudante ir direto para o ensinar outra pessoa sem ter aprendido anteriormente. 
De posse desse conhecimento, é importante que o professor apresente cada assunto de diversas maneiras, pois, somente em formatos distintos (áudio, vídeo, texto etc.), é possível atender a diferentes necessidades de aprendizagem dos alunos. No espaço virtual, contudo, cabe ao aluno entender-se como sujeito aprendente permanente e identificar sua forma particular de aprendizagem, permitindo-se aprender mais.

O professor e o aluno precisam entender, e o estudo das metodologias ativas comprova isso, que a sala de aula não é lugar de aprender, mas de entender (PIAZZI, 2015, p. 43). Transpondo ao contexto do ERE, o aluno aprende no momento assíncrono e entende no momento síncrono, o que permitirá uma aula dialógica, e não apenas expositiva.

Segundo Costa (2020, p. 12), o ERE não é igual a EaD. Os dois são on-line, no entanto, utilizam metodologias diferentes. O Ifal define, no Artigo 2 da Resolução 50/2020, da seguinte maneira:

Por Ensino Remoto Emergencial, no âmbito destas diretrizes institucionais, entende- se o conjunto de atividades pedagógicas realizadas pelo Instituto Federal de Alagoas, com ou sem mediação das tecnologias digitais, a fim de garantir atendimento acadêmico durante o período de restrições, enquanto não for possível a presença física de estudantes e servidores no ambiente institucional (IFAL, 2020, p. 22).

É recomendado por Costa (2020) que o ensino remoto seja composto por três trilhas distintas, mas que se entrecruzam: assíncrono, assíncrono interativo e síncrono. Respectivamente: aulas gravadas e disponibilizadas em algum Ambiente Virtual de Aprendizagem (AVA), plataforma que permita interação dos alunos, como um quiz ou um caçapalavras, e encontros on-line em que o professor e os alunos estejam conectados ao mesmo tempo. Nesse sentido, conferir a Figura 1 a seguir:

Figura 1 - Trilhas de Aprendizagem para o ERE 
Ricardo Jorge de Sousa Cavalcanti; Rossana Viana Gaia; Paulo Diego Cassiano Neves; Susan Maria Silva Valença

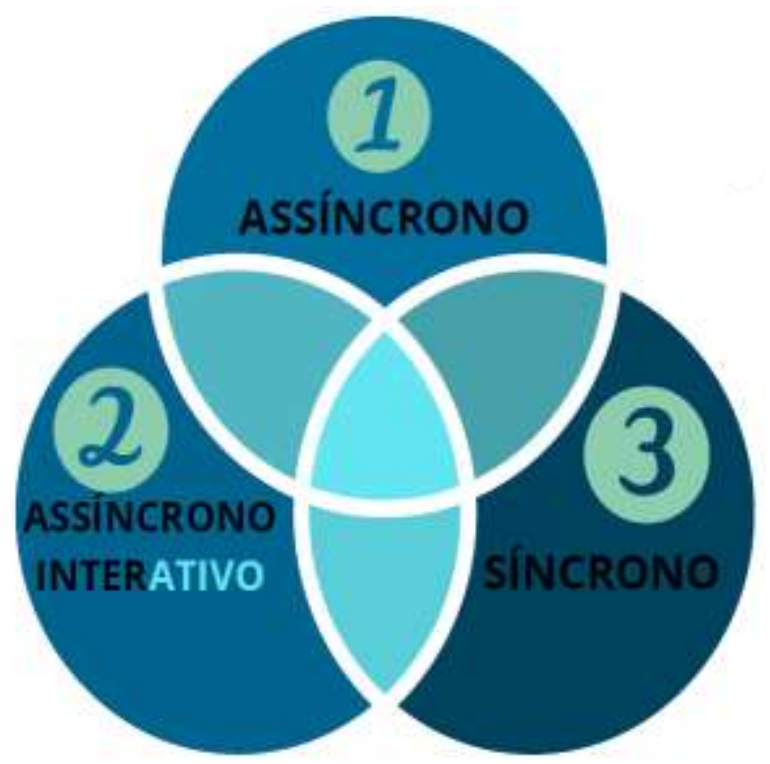

Fonte: Costa (2020, p. 14)

Educação a distância, conforme registra o MEC (BRASIL, 2019, on-line), “[...] é a modalidade educacional na qual alunos e professores estão separados, física ou temporalmente e, por isso, faz-se necessária a utilização de meios e tecnologias de informação e comunicação.” Contudo, na EaD, não há referência à utilização de momentos distintos como no ERE, além disso, as aulas EaD podem ter sido gravadas muito tempo antes de o aluno ter acesso a elas, desde que não tenham perdido o valor educacional nem, tampouco, se tornado ultrapassadas.

\section{Metodologias Ativas}

O princípio básico da metodologia ativa é a participação ativa do estudante executando alguma ação, seja ela mental, como combinar diversos assuntos para chegar a um resultado, ou física, como construir algum modelo ou montar uma apresentação. As TDIC ampliaram possibilidades de uso das metodologias ativas, contudo, muitas escolas, por desconhecimento e despreparo, ao serem forçadas por uma situação externa a prover aulas remotas aos seus alunos, como observado por Martins e Almeida (2020), tentaram fazer apenas uma transposição da aula presencial para a on-line, e isso não tem funcionado.

Um aluno sentado em frente ao seu computador, seja no seu quarto ou em qualquer cômodo da casa, tem substancialmente diversos incentivos para se distrair. Seu computador tem internet livre, e ele pode, sem sair do lugar e sem sair da sala de aula, jogar, assistir a um desenho 
de sua preferência ou até escutar música, e o professor não tem feedback do que está acontecendo. Por isso, o professor precisa capturar a atenção do aluno como forma para preservar o interesse e reduzir distrações possíveis. Essa estratégia potencialmente não ocorre em aula totalmente expositiva, na qual apenas o professor fala e que pode tornar-se cansativa e pouco atrativa aos estudantes.

Não se quer afirmar que a sala de aula on-line não poderá ser expositiva, mas, quando o professor assume o papel de apenas transmissor do conhecimento, o aluno pode ter menor interesse e aprender menos. Por isso, é importante se fazerem valer as técnicas e metodologias que promovam o envolvimento e a participação do estudante, sendo a tecnologia em rede uma estratégia de forte impacto, já que o domínio digital favorece comunicação interpessoal, publicidade de ideias e ampliação da empregabilidade futura, conforme destaca Moran (2018, p. 11).

Com isso, não pretendemos, nesta discussão, esgotar as possibilidades de atuação docente em contextos de ensino a respeito do uso de metodologias ativas. Em razão disso, elegemos autores e estudos, já referendados, para procedermos a tal discussão, que temos julgado como atual e necessária.

\subsection{Sala de aula invertida}

Consiste em oferecer aos alunos materiais de estudo prévio para que o momento em sala de aula seja dialógico, ou seja, por meio do qual os materiais que serão utilizados na aula são previamente indicados. A proposta é que o trabalho mais leve, sobretudo no que diz respeito à aproximação das ideias, seja realizado antes da aula e no momento do encontro entre professor e alunos “[...] os processos cognitivos mais complexos sejam estimulados, cabendo ao professor orientar e coordenar o debate" (BERGMANN. 2018, p. 11).

Para tornar o tempo de aula significativo, conforme registra Bergmann (2018), é importante que materiais prévios sejam disponibilizados em partes separadas e que estas partes, sempre que possível, estejam dispostas em mídias de formatos diferentes (áudio, texto, vídeo, jogos, etc...). Isso faz com que o aluno tenha maior trabalho cognitivo para ligar as partes do conteúdo e formar um bloco conceitual unificado em sua mente. 
Ricardo Jorge de Sousa Cavalcanti; Rossana Viana Gaia; Paulo Diego Cassiano Neves; Susan Maria Silva Valença

\begin{abstract}
$\mathrm{Na}$ abordagem da sala de aula invertida, o conteúdo e as instruções recebidas são estudados on-line, antes de o aluno frequentar a aula, usando as TDIC, mais especificamente, os ambientes virtuais de aprendizagem. A sala de aula torna-se o lugar de trabalhar os conteúdos já estudados, realizando atividades práticas como resolução de problemas e projetos, discussão em grupo e laboratórios (VALENTE, 2018, p.78-79).
\end{abstract}

Sabemos que a utilização de conceitos similares à sala de aula invertida é anterior à das TDIC, mas é indiscutível que a popularização do uso de computadores e celulares tornou mais fácil, porém não menos trabalhosa, para o professor, a aplicação dessa metodologia. Se o professor desejar ir além, partindo da sala de aula invertida, é possível a aplicação de outra metodologia ativa, a Aprendizagem Personalizada.

\title{
3.2 Aprendizagem personalizada
}

Esta metodologia possibilita ao aluno definir os caminhos e a velocidade da sua educação, já que visa a permitir que os alunos possam adaptar os conteúdos às suas necessidades, escolhendo o que estudar, no momento que julgar mais oportuno e onde quiser fazê-lo (VALENTE, 2018).

Mais uma vez, as TDIC aparecem como facilitadoras desse processo, pois permitem ao professor gerir melhor o progresso de cada aluno e facilitam ao aluno o acesso à informação e ao conhecimento para acelerar e continuar sua aprendizagem. Com efeito, uma das formas de se aplicar a metodologia de aprendizagem personalizada é por meio da utilização de outra metodologia ativa conhecida como Pedagogia por projetos.

\subsection{Pedagogia por projetos}

$\mathrm{Na}$ pedagogia por projetos, o professor pede que os alunos elaborem projetos para apresentar em seu componente curricular, os quais deverão atender a alguns critérios préestabelecidos e provocar os alunos para aprenderem ou aprimorarem habilidades necessárias à conclusão do projeto. $\mathrm{O}$ professor se insere nessa metodologia como um guia, apontando caminhos e, quando necessário, mediando conhecimentos.

\subsection{Metodologias em geral}


A utilização de metodologias ativas não deve impedir o professor de, em momentos que julgar necessário, mediar conhecimentos que julgue válidos aos estudantes. Contudo, é importante evidenciar que o responsável pelo aprendizado é o aluno. Todas as metodologias ativas se baseiam neste princípio: o aluno como autor do próprio conhecimento e responsável pela própria aprendizagem, pois, ao assumir a rota da sua educação, constrói o seu próprio conhecimento, além de definir o que interessa problematizar, com impactos no seu futuro. Nesse sentido, o professor orienta sobre os assuntos abordados e não se limita a ser transmissor do conhecimento, pois, quando evita a educação bancária, conforme critica Paulo Freire (1996), favorece a interatividade.

\section{Minicurso}

De posse desses conhecimentos, organizamos um minicurso para os professores em formação dos períodos iniciais do curso de Letras-Português. O minicurso teve seu primeiro módulo já ministrado trazendo-nos descobertas, reflexões e dificuldades que foram encontradas durante o seu período de realização.

O minicurso ofertado, cujo título foi "Abordagens ativas e multiletramento(s) no ensino de LP”, foi ofertado contemplando 20 vagas (com período de inscrição entre os dias 10 e 12 de novembro de 2020), e ministrado entre os dias 17 e 29 de novembro desse mesmo ano, perfazendo a carga horária total de $20 \mathrm{~h}$.

Figura 2 - Campanha de inscrição do minicurso

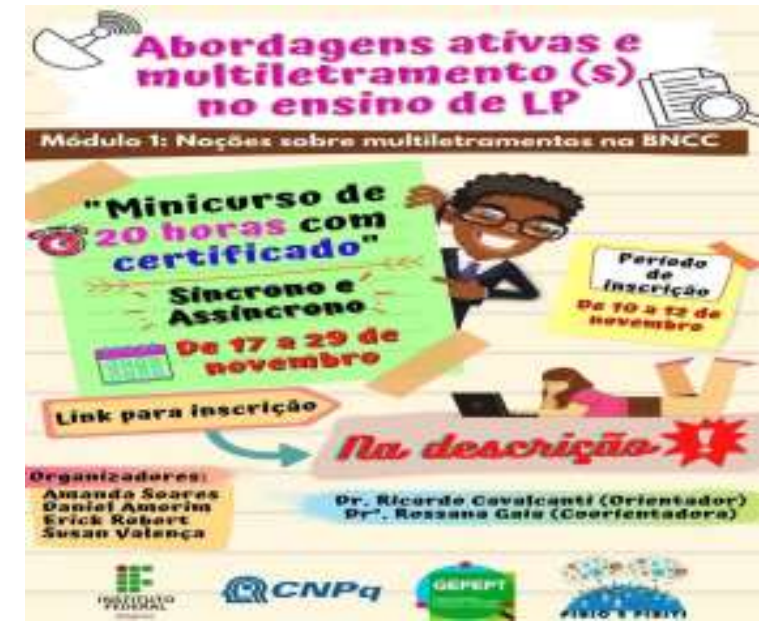

Fonte: Dados da pesquisa, 2020. 
Ricardo Jorge de Sousa Cavalcanti; Rossana Viana Gaia; Paulo Diego Cassiano Neves; Susan Maria Silva Valença

O minicurso foi elaborado utilizando a metodologia ativa Sala de Aula Invertida e abordou no seu primeiro módulo, principalmente, a temática envolta aos multiletramentos e à BNCC. Foi elaborado um AVA (Ambiente Virtual de Aprendizagem), utilizando o Google Classroom, no qual eram disponibilizados os materiais de aprendizagem em diversos formatos e, posteriormente, era promovido um debate acerca dos temas abordados. Os formatos de conteúdo dispostos foram textos, hipertextos, vídeos, podcasts e artigos científicos. Os debates ocorreram de forma assíncrona por meio de comentários realizados no próprio AVA e em grupos do Whatsapp (em dois momentos) e de forma síncrona durante uma mesa redonda, que, infelizmente, não teve muita adesão por parte dos cursistas, pois coincidiu com a realização de outras atividades da instituição lócus de nossa atuação/investigação.

Contamos com 28 pedidos de inscrição. Desses, 9 cadastros foram incompletos, 2 desistiram (cadastraram-se no curso, mas nunca acessaram o AVA), 17 concluíram o minicurso, e, após a conclusão, 1 aluno deletou a conta do Google, que foi utilizada para acesso ao AVA, que ocasionou a perda de todos os dados que se referiam a ela.

Foi solicitado aos participantes que preenchessem um formulário intitulado "Perfil Cursista”, trazendo-nos informações importantes, que conduziram o formato do minicurso. 15 participantes responderam ao formulário, conforme podem ser visualizados os dados extraídos na Figura 3:

Figura 3 - Faixa Etária

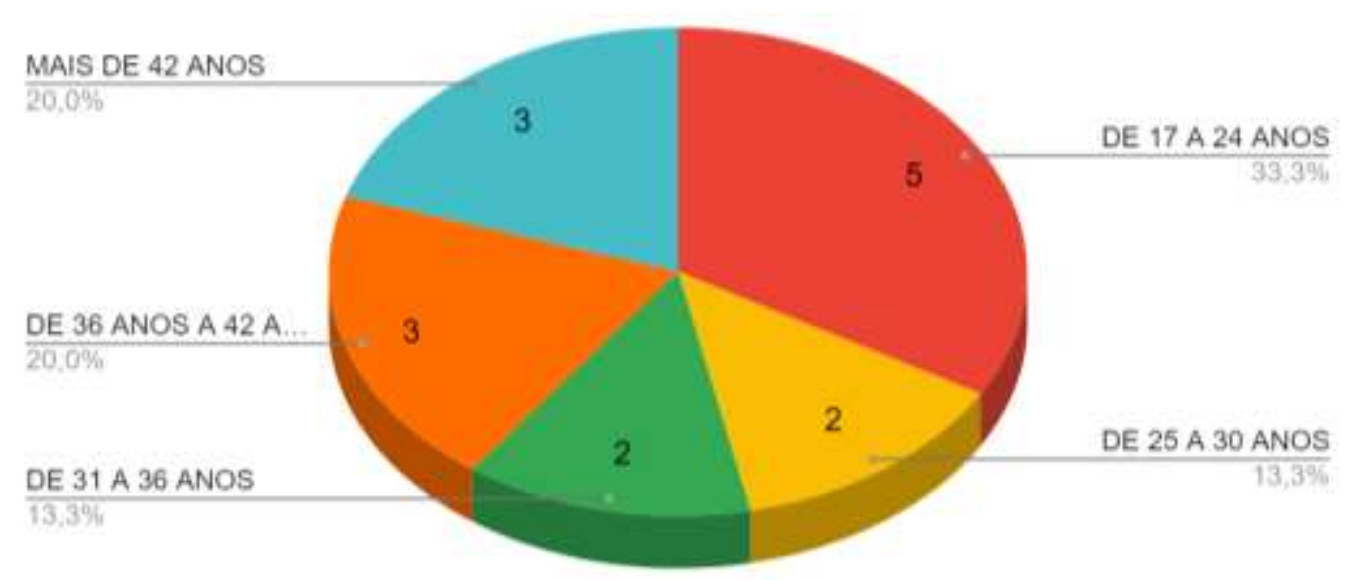

Fonte: Dados da pesquisa, 2020 . 
Como se pode observar, houve uma maior participação de estudantes nas faixas etárias de 17 a 24 anos, correspondente a 33,3\%; 13,3\% de participação entre 25 e 30 anos; bem como $13,3 \%$ na faixa etária de 31 a 36 anos. Estudantes entre 36 e 42 anos representam $20 \%$ dos participantes; e $20 \%$ acima dos 42 anos. Apesar de os números percentuais uma maior predominância no público concentrado na faixa etária dos 17 aos 24 anos (33,3\%), as demais faixas etárias, correspondentes a $66,7 \%$, indicam que o público participante do minicurso é diversificado em relação ao fator idade, o que também pode configurar uma análise a respeito da necessidade de participação de eventos nesse formato na possibilidade de interações intergeracionais.

Figura 4 - Eventos virtuais que participou durante a pandemia

6

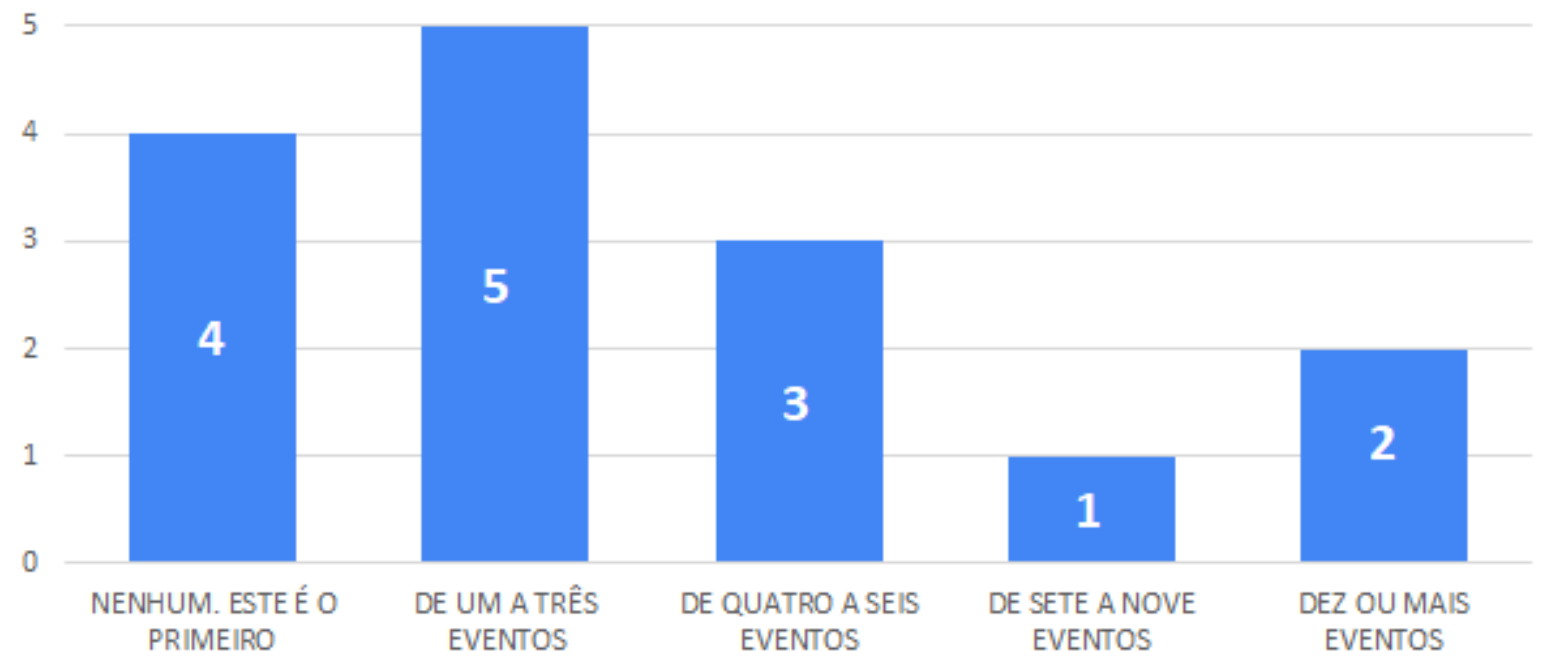

Fonte: Dados da pesquisa, 2020.

A maioria dos participantes havia participado de algum tipo de evento on-line durante a pandemia, contudo $26 \%$ deles tiveram como primeiro evento o minicurso. 
Ricardo Jorge de Sousa Cavalcanti; Rossana Viana Gaia; Paulo Diego Cassiano Neves; Susan Maria Silva Valença

Figura 5 - Alegação de dificuldade para ler em telas

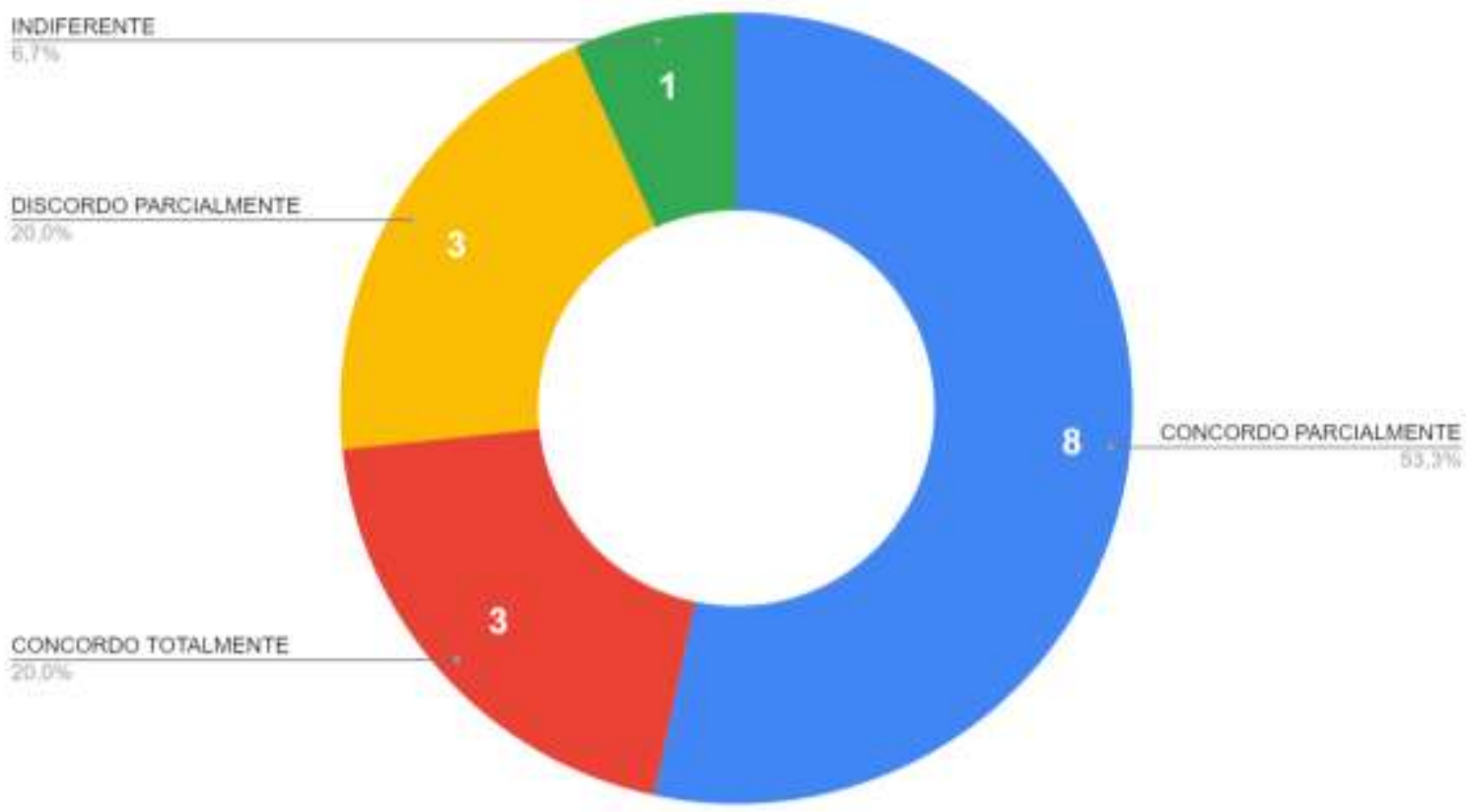

Fonte: Dados da pesquisa, 2020.

Os dados presentes na Figura 5 nos foram cruciais, isto é: apenas 1 estudante alegou não ter qualquer problema para leitura em telas. Isso guiou a escolha dos materiais a serem disponibilizados, ou seja, em razão disso, demos preferência a formatos de textos que facilitavam a visualização em tela como slides, além da utilização de materiais que não precisavam de tela, tais como: podcasts e, quando necessário, para acesso a textos mais complexos, optamos por manuscritos já formatados para impressão, a exemplo de artigos científicos em PDF, e evitamos, assim, o uso de materiais que exigiriam maior uso da tela como hipertextos. 
Figura 6 - Forma de acesso à informação

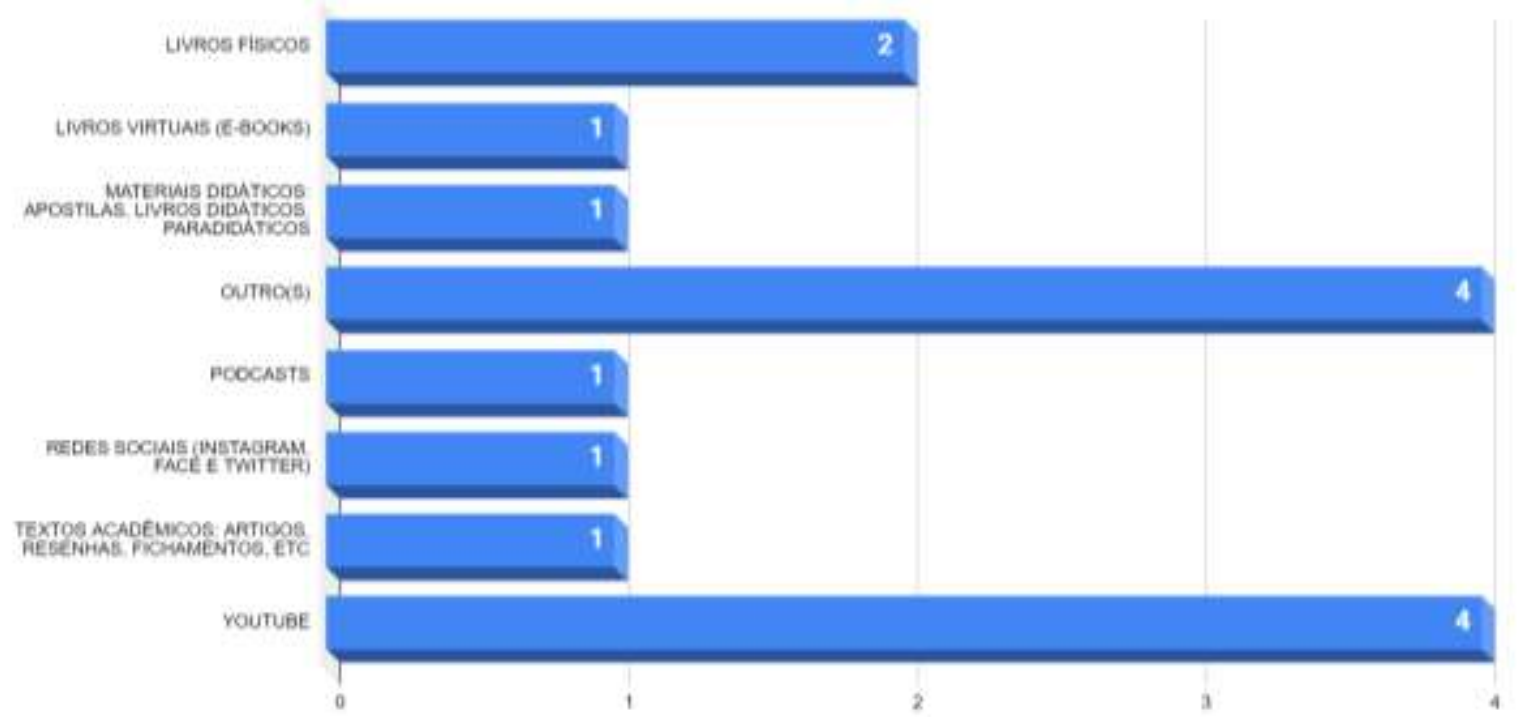

Fonte: Dados da pesquisa, 2020.

A principal forma de acesso à informação identificada foi o YouTube. Como um dos objetivos do minicurso era promover uma ambientação aos multiletramentos, além de ensinar sobre eles, foi definida a utilização de mídias diversas, como: podcasts, vídeos, slides e textos para impressão.

Figura 7 - Tipo de dispositivo utilizado para acessar as aulas

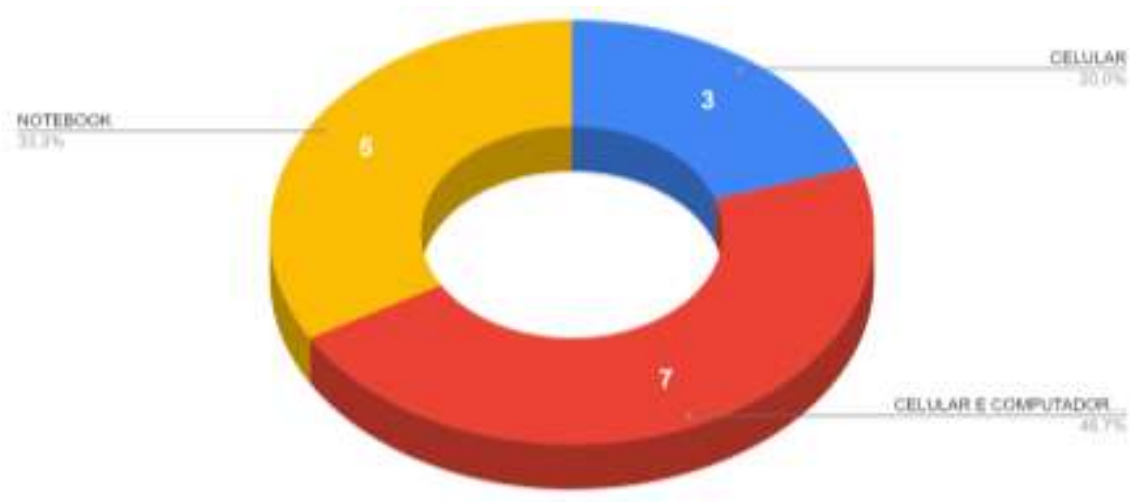

Fonte: Dados da pesquisa, 2020.

Como demonstra a Figura 7, 20\% dos cursistas utilizavam exclusivamente o celular para assistir às aulas. Por isso, definiu-se a elaboração de materiais dimensionados para essa realidade, sendo descartado, por exemplo, trabalhos dimensionados com formatos de edição, 
Ricardo Jorge de Sousa Cavalcanti; Rossana Viana Gaia; Paulo Diego Cassiano Neves; Susan Maria Silva Valença

como ABNT e APA. O trabalho solicitado para conclusão do minicurso foi um artigo de opinião, entre os quais, apenas quatro cursistas entregaram.

Figura 8 - Percepção quanto à formação para o trabalho com TDIC no ensino de LP

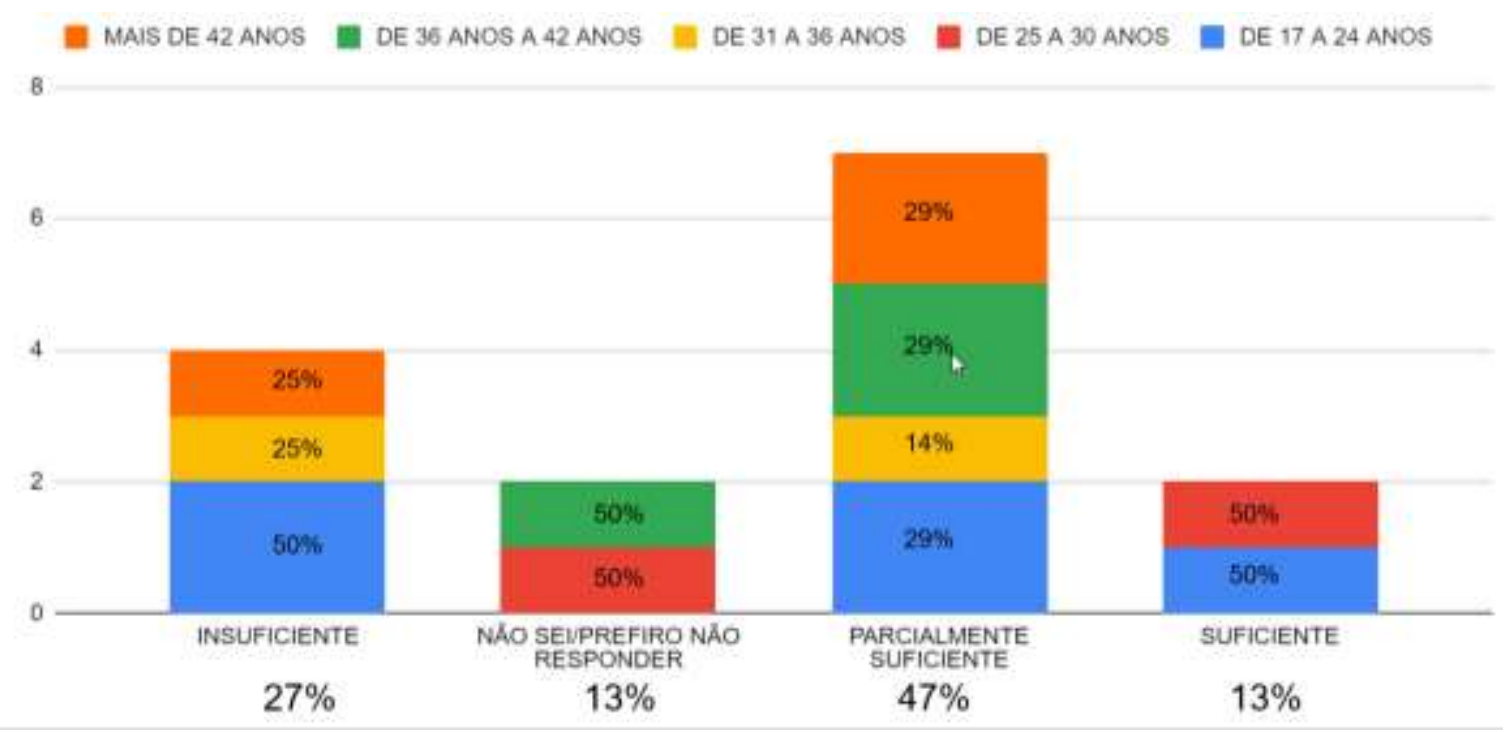

Fonte: Dados da pesquisa, 2020.

Perguntamos aos estudantes como percebiam o ensino das TDIC para uso no ensino de Língua Portuguesa. As respostas confirmaram novamente a necessidade desse minicurso, pois apenas $13 \%$ dos estudantes veem como suficiente o ensino de TDIC na instituição; enquanto $47 \%$ afirmaram ser parcialmente suficiente; $13 \%$ não souberam responder; e $27 \%$ alegaram ser insuficiente. Os que utilizaram esse último argumento se inserem nas faixas etárias mais baixas, ou seja, entre 17 e 30 anos, porém, como outros participantes dessas faixas responderam a todas as outras opções, não foi possível identificar, nesse questionamento, uma tendência causada pela idade.

Também foi feita uma análise sobre a participação dos estudantes durante o minicurso. Identificou-se que, dos 16 alunos cadastrados no AVA, 50\% realizaram as atividades solicitadas dentro do próprio AVA, porém, quando foi solicitado acesso a um grupo do WhatsApp para realização da atividade, tivemos a participação de $31 \%$ no primeiro momento e $25 \%$ no segundo momento. A análise das interações indica que as participações dos alunos no AVA tiveram uma média de 1,5 comentários por participante; no WhatsApp, a média foi de 2,5 no primeiro momento e 2,75 na segunda etapa. 
A análise dos dados possibilitou concluir que, apesar do uso do WhatsApp ter provocado uma média de comentários maior, foi um ambiente virtual no qual se constatou menor adesão dos cursistas. Contudo, uma hipótese possível para haver redução de comentários pode ser decorrente da mudança de uma plataforma para a outra e não pela plataforma em si.

A análise dos artigos de opinião produzidos indicou que os objetivos definidos para a realização do estudo foram, até este momento, parcialmente alcançados, dado que os cursistas demonstraram conhecimento e olhar crítico sobre os temas abordados, além de terem indicado informações sobre a BNCC, não obstante a identificação de desafios a serem enfrentados, alegados pelos cursistas. A seguir, por meio do Quadro 1, identifica-se a opinião de um dos cursistas na etapa em que aborda a contribuição do primeiro módulo do minicurso para sua formação.

Quadro 1 - Percepção de cursista quanto ao minicurso ofertado [...] foram selecionados como instrumentos de aprendizagem: podcast, artigos em PDF, vídeos curtos e WhatsApp. Todos os meios tecnológicos adquiridos foram importantes para a nossa aprendizagem. O podcast ouvido nos fez refletir como docentes a importância dos processos de multiletramentos na educação básica que proporciona aos estudantes experiencias que contribuam para uma participação significativas nas diversas práticas sociais (Cursista).

Fonte: Dados da pesquisa, 2020.

Os dados dispostos correspondem ao momento da primeira etapa do minicurso, cuja conclusão somente estava prevista para abril de 2021, quando seria ofertado o segundo módulo correspondente à pesquisa, no âmbito do PIBITI/Ifal, voltada às metodologias ativas, aos multiletramentos e as suas inter-relações com a BNCC. Convém destacar tais informações já que à época da escrita deste artigo e da tabulação dos primeiros dados para o estabelecimento desta discussão a pesquisa ainda se encontrava com o status de "em andamento". Salienta-se que no segundo módulo, visando ao aprofundamento nas metodologias ativas, visto que o primeiro foi uma introdução à temática. Ainda, nesse sentido, possivelmente haverá um terceiro módulo a fim de que haja uma maior explanação a respeito da parte prática para uso de ferramentas específicas. Com a finalização de todo o processo investigativo, o minicurso será compilado e disposto no eduCAPES, repositório de licenciamento gratuito pelo Criative Commons, cujo acesso será livre àqueles interessados pela temática.

Os resultados parciais da pesquisa confirmam que o uso de metodologias ativas incentiva a participação dos alunos e auxilia na compreensão a respeito dos temas abordados. Ademais, foi identificado que a mudança de plataformas de comunicação promove menor participação 
Ricardo Jorge de Sousa Cavalcanti; Rossana Viana Gaia; Paulo Diego Cassiano Neves; Susan Maria Silva Valença

dos alunos. Os dados indicaram que, para garantir maior número de participantes efetivos, é mais eficaz manter toda interação em uma única plataforma.

É importante ressaltar a ausência de estatísticas no AVA Google Classroom que subsidiem o professor com informações para tomada de decisões, tanto sobre quais os materiais estão sendo efetivamente utilizados pelos alunos, como saber a quanto de um vídeo um aluno assistiu ou se ele abriu um link ou arquivo. Nota-se também a falta de informações sobre os perfis dos alunos, sendo necessária coleta dessas informações em um formulário desassociado dos demais dados, a fim de se promover o cruzamento das informações do perfil com as informações acadêmicas de forma manual. É imprescindível ponderar que a plataforma mencionada ainda é imatura, na perspectiva de apenas criar dificuldades para, num futuro "próximo", vender facilidades (uma plataforma mais complexa) ou, como ponderam Martins e Almeida (2020, p. 5), “[...] quando os serviços dessas empresas são gratuitos, nós (nossos dados) somos o produto e muitos desdobramentos podem ocorrer".

\section{Considerações finais}

A pesquisa, em processo de execução, ainda que evidencie um resultado parcial aparentemente satisfatório, apresenta algumas etapas a executar adiante, que podem ampliar a contribuição aos discentes do curso de Letras - Português/ Ifal, professores em formação inicial, que efetivamente participaram do processo. Até o presente momento, investiga-se sobre os conceitos de metodologias ativas e ensino híbrido e promove-se, por meio de cada etapa do minicurso, uma reflexão para que os participantes adquiram, em momentos dialógicos, um olhar crítico sobre os temas abordados. Nas próximas etapas, intencionamos aprofundar essa reflexão e dialogaremos sobre ferramentas e metodologias específicas para a aplicação dos conceitos demonstrados.

O estudo realizado até o presente momento também nos trouxe reflexões sobre as tecnologias e mídias que iremos utilizar para trazer essas discussões aos inscritos, tendo em vista as dificuldades encontradas e as descobertas feitas por meio do formulário perfil do cursista. Devido a essas descobertas recentes, será possível ajustar a metodologia do minicurso e usar as TDIC de forma a engajar um maior número de participantes em etapas futuras.

Por fim, conclui-se que os resultados alcançados confirmam a base teórica analisada, já que se identifica interesse dos alunos no trabalho com a virtualidade, sendo os objetivos desta 
primeira etapa alcançados. Outro aspecto positivo foi para a própria equipe de pesquisadores, bem como para os estudantes cursistas, pois se verificou uma ampliação do olhar crítico sobre um tema atual e relevante, sobretudo, ao seu processo de formação. Destaque-se ainda que, a partir das próprias análises, dificuldades e sugestões dos cursistas, foi possível remodelar o estudo e identificar potencial para ampliar a oferta de módulos.

\section{Referências}

ANECLETO, U. C.; MIRANDA, J. D. O. Multiletramentos e práticas de leitura, escrita e oralidade no ensino de Língua Portuguesa na educação básica. Pontos de Interrogação, v. $6,2016.2$ n. 2 Disponível https://www.revistas.uneb.br/index.php/pontosdeint/article/view/3295. Acesso em: 27/03/2021.

BERGMANN, J. Aprendizagem invertida para resolver o problema do dever se casa. Porto Alegre: Penso, 2018.

BRASIL. Ministério da Educação. Base Nacional Comum Curricular. Brasília, 2018.

BRASIL. Ministério da Educação. O que é educação a distância?. 2019. Disponível em: http://portal.mec.gov.br/component/content/article?id=12823:o-que-e-educacao-adistancia. Acesso em: 29/03/2021.

CASTELLS, M. A sociedade em rede. A era da informação: economia, sociedade e cultura. Vol 1. 7. ed. revista e ampliada. São Paulo: Paz e Terra, 2003.

COSTA, M. A. da. Metodologias ativas de aprendizagem aplicadas ao ensino remoto emergencial. CEFET-MG: Belo Horizonte, 2020.

DELOITTE. Global Mobile Consumer Survery Brasil. Brasil, 2019. Disponível em: https://pesquisas.lp.deloittecomunicacao.com.br/global-mobile-consumer-19._Acesso em: 22/03/2021.

FALCÃO, S. P. Aceleração temporal e estresse docente. In: CITELLI, A. (org.) Educomunicação: Comunicação e educação: Os desafios da aceleração social do tempo. São Paulo: Paulinas, 2017, p. 27-46.

FREIRE, P. Pedagogia da autonomia: saberes necessários à prática educativa. São Paulo: Paz e Terra, 1996.

GAIA, R. V. O jornal impresso na escola: possíveis caminhos para a cidadania. 2000. Dissertação (Mestrado) - Universidade Federal da Paraíba, João Pessoa, 2001.

IFAL. Direção Geral. Edital No 01/2020. Seleção para o auxílio conectividade e projeto alunos conectador. Maceió, 2020. Disponível em: https://www2.ifal.edu.br/campus/maceio/noticias/ifal-maceio-abre-segunda-etapa-paraadesao-ao-auxilio-conectividade. Acesso em: 22/03/2021. 
Ricardo Jorge de Sousa Cavalcanti; Rossana Viana Gaia; Paulo Diego Cassiano Neves; Susan Maria Silva Valença

IFAL. Reitoria. Resolução $\mathbf{N}^{\mathbf{5}}$ 50/2020. Maceió, 2020. Disponível em: https://www2.ifal.edu.br/acesso-a-informacao/institucional/orgaos-colegiados/conselhosuperior/arquivos/resolucao-ndeg-50-2020-aprova-as-diretrizes-para-o-ensino-remotoemergencial-no-ifal.pdf/view. Acesso em: 22/03/2021.

LUCENA, S. Culturas digitais e tecnologias móveis na educação. Educar em Revista, 2016. Disponível em: https://doi.org/10.1590/0104-4060.43689. Acesso em: 22/03/2021.

MARTINS, V.; ALMEIDA, J. (2020). Educação em tempos de pandemia no brasil: saberes fazeres escolares em exposição nas redes. Revista Docência e Cibercultura, 2020. Disponível em: https://doi.org/10.12957/redoc.2020.51026. Acesso em: 24/03/2021.

MORAN, J. Metodologias ativas para uma aprendizagem mais profunda. In: BACICH, L.; MORAN, J. (orgs). Metodologias ativas para uma educação inovadora: uma abordagem teórico-prática. Porto Alegre: Penso, 2018, p.01-15.

NOVELI, Marcio. Do Off-line para o Online: a Netnografia como um Método de Pesquisa ou o que pode acontecer quando tentamos levar a Etnografia para a Internet? Organizações em Contexto. São Paulo, v. 12, n. 6, p.107-133, 2010. Semestral.

PIAZZI, P. Aprendendo Inteligência: Manual de instruções do cérebro para estudantes em geral. 3. ed. São Paulo: Goya, 2015.

ROJO, R. Pedagogia dos Multiletramentos: diversidade cultural e linguagens na escola. In: ROJO, R. H. R.; MOURA, E. (Orgs). Multiletramentos na escola. São Paulo: Parábola Editorial, 2012, p.11-31.

SILVA, J. A. O.; RANGEL, D. A.; SOUZA, I. A. de. Docência superior e ensino remoto: relatos de experiências numa instituição de ensino superior privada. Revista Docência do Ensino superior, v.10, 2020. Disponível em: https://doi.org/10.35699/2237-5864.2020.24717. Acesso em: 25/03/2021.

VALENTE, J. A. A sala de aula invertida e a possibilidade do ensino personalizado: uma experiência com a graduação em midialogia. In: VALENTE, J. A.; BACICH, L.; MORAN, J. (Org.). Metodologias ativas para uma educação inovadora: uma abordagem teórico-prática. Porto Alegre: Penso, 2018, p.26-44.

\section{Autores:}

Ricardo Jorge de Sousa Cavalcanti. Doutor em Linguística pela Universidade Federal de Alagoas (Ufal). Estágio pós-doutoral em Linguística Aplicada pela Universidade Federal de Alagoas (Ufal). Professor do Instituto Federal de Educação, Ciência e Tecnologia de Alagoas (Ifal), atuando no Curso de Licenciatura em Letras-Português, Campus Maceió; e no Mestrado Profissional em Educação Profissional e Tecnológica, Campus Benedito Bentes (ProfEPT/Ifal). Pesquisador vinculado ao Grupo de Estudos e

Pesquisas em Educação Profissional e Tecnológica (GEPEPT/CNPq/ProfEPT/Ifal). 
Rossana Viana Gaia. Doutora em Linguística pela Universidade Federal de Alagoas (Ufal). Estágio pós-doutoral na área de educomunicação no PPGCIn/UFPE. Professora do Instituto Federal de Educação, Ciência e Tecnologia de Alagoas (Ifal), atuando no Curso de Licenciatura em Letras-Português, Campus Maceió; e no Mestrado Profissional em Educação Profissional e Tecnológica, Campus Benedito Bentes (ProfEPT/Ifal). Pesquisadora vinculada ao Grupo de Estudos e Pesquisas em Educação Profissional e Tecnológica (GEPEPT/CNPq/ProfEPT/Ifal).

Paulo Diego Cassiano Neves. Licenciando do Curso de Letras-Português do Instituto Federal de Educação, Ciência e Tecnologia de Alagoas (Ifal), Campus Maceió.

Susan Maria Silva Valença. Licencianda do Curso de Letras-Português do Instituto Federal de Educação, Ciência e Tecnologia de Alagoas (Ifal), Campus Maceió. 